\title{
Co-O Evaporated Films for Magnetic Recording Media
}

\author{
R. SUGITA ${ }^{1}, K$. TOHMA² and T. ISHIDA ${ }^{2}$
}

1) Department of Media and Telecommunications Engineering, Ibaraki University 4-12-1 Nakanarusawa-cho, Hitachi-shi, Ibaraki 316, Japan

2) AVC Products Development Laboratory, Matsushita Electric Industrial Co., Ltd. 1006 Kadoma, Kadoma-shi, Osaka 571, Japan

\begin{abstract}
The coercivity of Co-O obliquely deposited films formed directly on the polymer substrate increases with increasing thickness up to around $40 \mathrm{~nm}$, and decreases over $50 \mathrm{~nm}$. A CoO underlayer makes the coercivity and the uniaxial magnetic anisotropy of the films high owing to an improvement of c-axis orientation of hep Co. The morphological texture of the under layer is considered to promote the c-axis orientation of the films. The Co-O films are endowed with resolution potential high enough to attain Gbit/inch ${ }^{2}$ order of areal recording density. The comparison between the $\mathrm{Co}-\mathrm{O}$ film and hard disk media in the recording properties shows that the Co-O tape has much higher reproduced voltage than the disk for magnetoresistive (MR) reproduction use.
\end{abstract}

\section{I . INTRODUCTION}

Co-O evaporated films are now on the market as thin film magnetic recording tapes for digital VCR (DVC) and some streamers. Having high reproduced voltage and low noise, the films have attained recording density of $300 \mathrm{M}-400 \mathrm{Mbit} / \mathrm{inch}^{2}$. In order to improve high density recording performance, it is necessary to make the film thickness thinner. However, as film thickness becomes thin, magnetic properties deteriorate. $\mathrm{CoO}$ underlayers are effective to improve magnetic properties in thin thickness region [1].

This paper presents the relation between thickness and magnetic properties, the effect of underlayers and recording characteristics compared with hard disks.

\section{II . MEDIA PREPARATION}

Tape media were prepared by using a webcoater type continuous vacuum deposition system. Co atoms were deposited in an oxygen atmosphere to form $\mathrm{Co}-\mathrm{O}$ films and $\mathrm{CoO}$ underlayers on a polyethilane telephtalate film. The minimum incident angle to the substrate was $60^{\circ}$, where the incident angle is defined as the angle between incident vapor beam direction and the film normal of the substrate.

\section{MAGNETIC PROPERTIES AND MICROSTRUCTURE OF Co-O FILMS}

Closed circles in Fig.1 show the thickness dependence of the coercivity $H_{c}$ of Co-O films with the saturation magnetization $M_{\mathrm{s}}$ of $600 \mathrm{kA} / \mathrm{m}$, where $H_{c}$ was measured in transport direction of the substrate. $H_{\mathrm{c}}$ increases with increasing the thickness up to $40 \mathrm{~nm}$, and decreases in the region

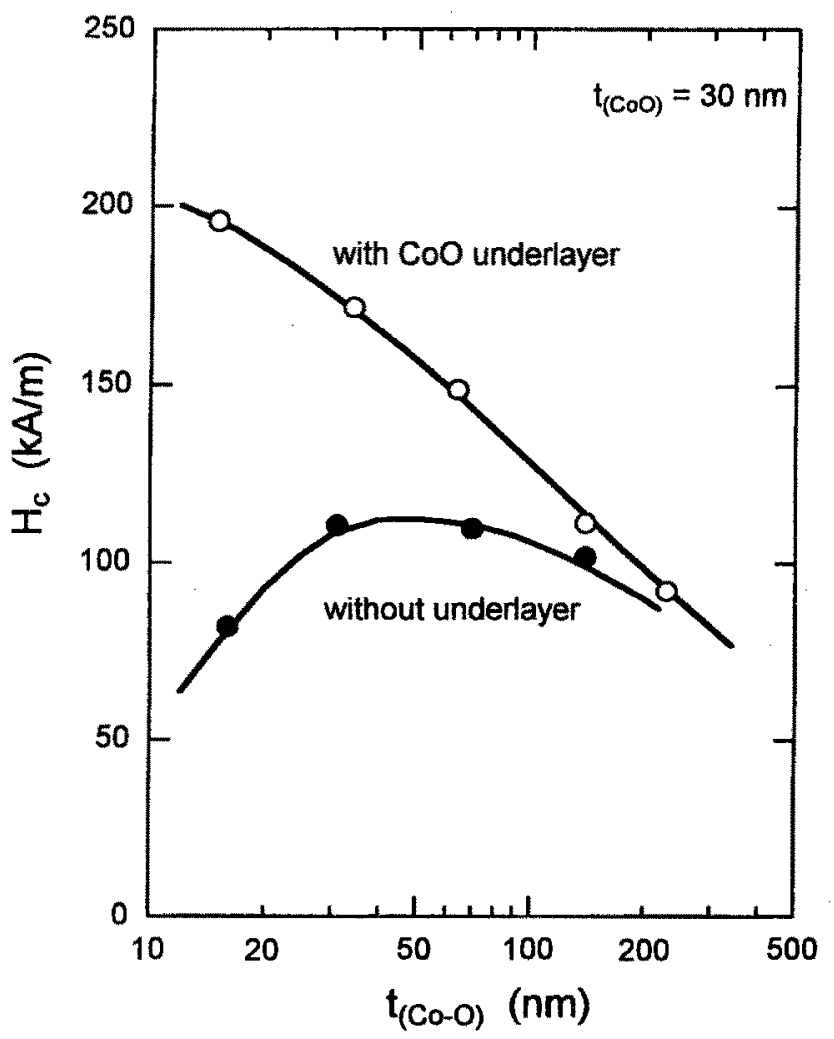

Fig. 1. Co-O film thickness dependence of $H_{c}$.

over $50 \mathrm{~nm}$.

Closed circles in Fig.2 show the thickness dependence of the magnetic anisotropy energy $K_{\mathrm{w}}$ determined by $\beta+45^{\circ}$ torque analysis method [2]. $K_{\mathrm{u}}$ increases with increasing the thickness. This is because of the improvement of c-axis orientation in the direction of grain growth with increasing the thickness.

Magnetocrystalline anisotropy field of grains 


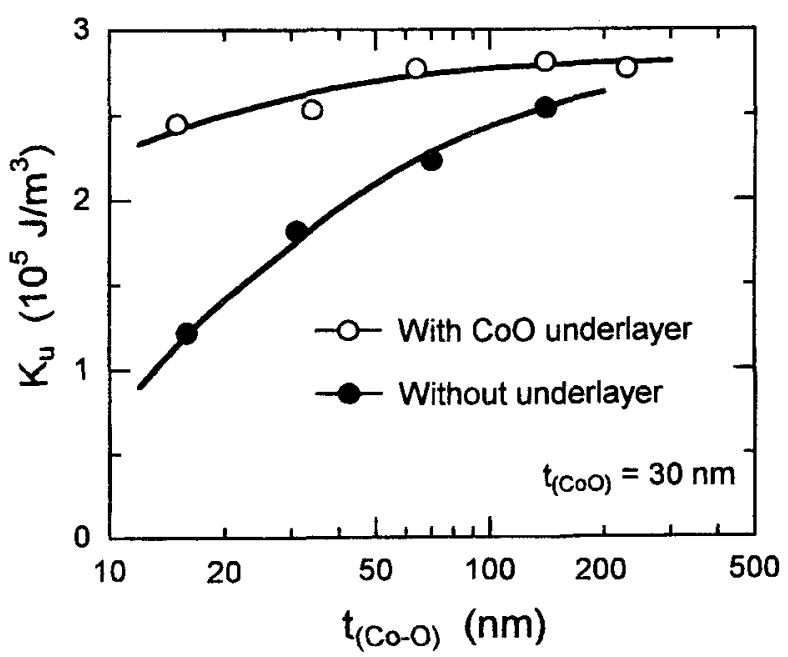

Fig. 2. Co-O film thickness dependence of $K_{\mathrm{u}}$.
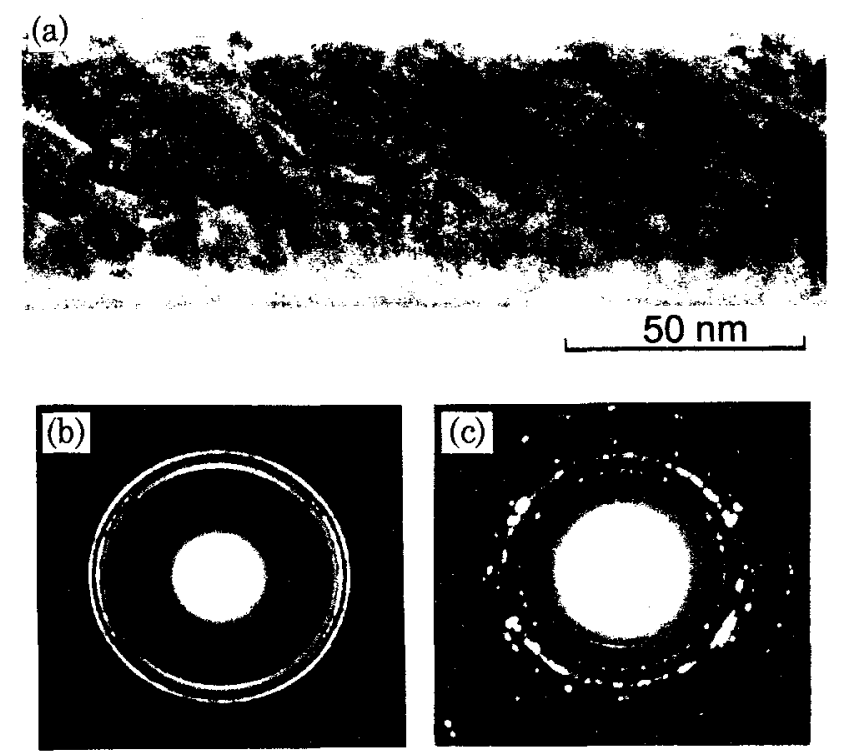

Fig.3. A cross sectional TEM image (a), electron diffraction patterns in in-plane (b) and cross section (c) of a $\mathrm{Co}-\mathrm{O}$ film with a $\mathrm{CoO}$ underlayer.

$H_{\mathrm{k}}$ grain was independent on the thickness. Hence, $H_{c, \text { av }} / H_{\mathrm{k}}$ grain, which is considered as an index of magnetic isolation of grains [3], shows the same tendency as the thickness dependence of $H_{c}$, where $H_{c \text {,av }}$ is an average value of $H_{\mathrm{c}}$ measured in transport direction and width direction of the substrate. The thickness dependence of $H_{c, \text { av }} / H_{k}$ grain and the change of $K_{\mathrm{u}}$ suggest the following. The Co-O films have low $H_{\mathrm{c}}$ when the thickness is below $30 \mathrm{~nm}$, since the anisotropy energy is low and the magnetic separation among grains is not enough. $H_{\mathrm{c}}$ of the films becomes the highest around the thickness of $40 \mathrm{~nm}$, because the magnetic anisotropy energy is high and the magnetic
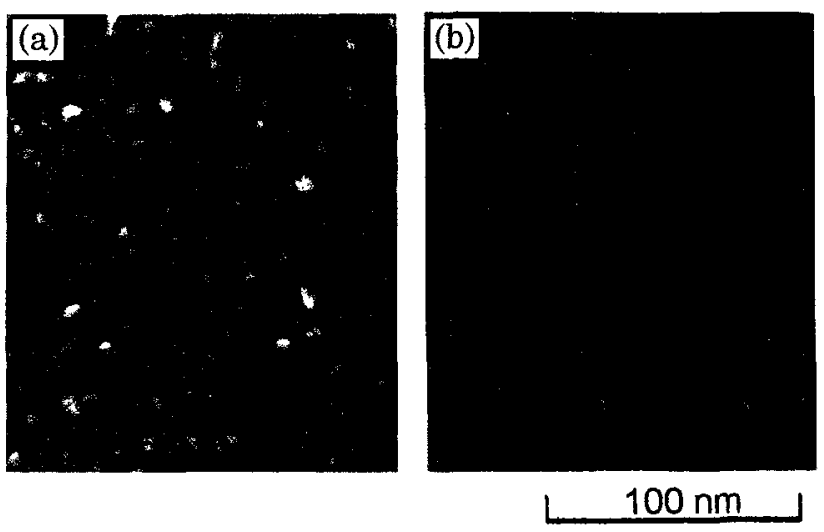

Fig.4. SEM images of a $\mathrm{CoO}$ underyayer (a) and an $\mathrm{Al}_{2} \mathrm{O}_{3}$. underlayer (b).

separation is promoted. When the thickness is over $50 \mathrm{~nm}, H_{\mathrm{c}}$ becomes low, because the magnetic separation is not enough in spite of high anisotropy energy.

\section{IMPROVEMENT OF MAGNETIC PROPERTIES USING UNDERLAYERS}

We investigated underlayers to make $H_{c}$ of the Co-O films high in the thin thickness region. Open circles in Fig. 1 show the thickness dependence of $H_{\mathrm{c}}$ of the $\mathrm{Co}-\mathrm{O}$ films with the CoO underlayers. $H_{\mathrm{c}}$ of the films with the underlayers increases drastically in thin thickness region compared with the films without ones.

Open circles in Fig.2 show the thickness dependence of $K_{\mathrm{u}}$ of the Co-O films with the $\mathrm{CoO}$ underlayers. The films with the underlayers have higher $K_{\mathrm{u}}$ than those without ones. Difference of $K_{\mathrm{u}}$ between the films with and without underlayers is especially notable in thin thickness region.

Figure 3 shows a cross sectional transmission electron microscope (TEM) image (a), an electron diffraction pattern in in-plane (b) and cross section (c) of a $\mathrm{Co}-\mathrm{O}$ film with a $\mathrm{CoO}$ underlayer. The inplane diffraction pattern shows that the c-axis of the hcp Co preferentially grows in transport direction of the substrate. On the other hand, the preferential orientation was not observed in inplane for the $\mathrm{Co}-\mathrm{O}$ films without the $\mathrm{CoO}$ underlayers. The c-axis of the hcp Co also preferentially grows in the growing direction of columnar grains in cross section, and the c-axis orientation is more remarkable than that of the $\mathrm{Co}-\mathrm{O}$ films without the $\mathrm{CoO}$ underlayers.

Figure 4 shows scanning electron microscope (SEM) images of a $30 \mathrm{~nm}$ thick $\mathrm{CoO}$ underlayer (a) and a $40 \mathrm{~nm}$ thick $\mathrm{Al}_{2} \mathrm{O}_{3}$ underlayer (b), where the latter had no effect like the former. In the $\mathrm{CoO}$ 


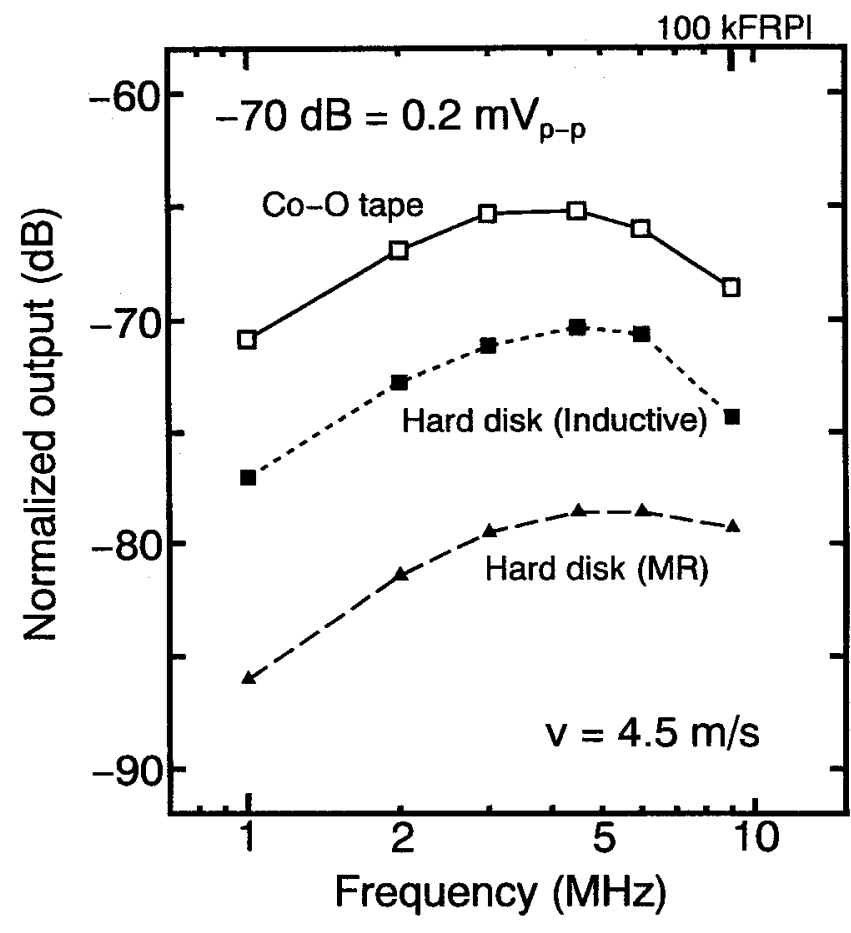

Fig.5. Recording characteristics of a $\mathrm{Co}-\mathrm{O}$ tape and hard disks.

underlayer, highly isolated grains are arranged uniformly, whose diameter is about $10 \mathrm{~nm}$. In the $\mathrm{Al}_{2} \mathrm{O}_{3}$, the grains of 20-30 $\mathrm{nm}$ diameter combine each other and grain boundary is unclear.

From the surface pictures shown in Fig.4, the following is considered as a role of the $\mathrm{CoO}$ underlayers which promotes the c-axis orientation of the Co-O films. Atoms for the magnetic layer deposited obliquely on the substrate are accumulated almost vertically on the convex surface of $\mathrm{CoO}$ grains. Since vertically deposited Co films have a tendency such that the c-axis orients in the incident beam direction, the c-axis of the obliquely deposited $\mathrm{Co}-\mathrm{O}$ films are apt to orient in oblique direction. Moreover, the self-shadowing effect is more remarkable for the $\mathrm{Co}-\mathrm{O}$ films formed obliquely on the $\mathrm{CoO}$ underlayers, resulting in the promoted separation among the grains.

\section{RECORDING CHARACTERISTICS}

A read/write experiment of tapes was carried out by using a drum tester, while that of hard disks were done by using a spin stand.

The Co-O films showed reproduced voltage recognizable up to $600 \mathrm{kFRPI}$, and superior recording resolution over the recording density of $400 \mathrm{kFRPI}$. However, for helical scan type magnetic tape recording appliances, progress to high density recording becomes slow, because of issues of head tracking and difficulty of using MR heads.

Figure 5 shows a comparison of recording characteristics between a Co-O tape and some hard disks. The Co-O tape has $B_{\mathrm{r}} \cdot t$ of $772 \mathrm{G} \cdot \mu \mathrm{m}$ and $H_{c}$ of $120 \mathrm{kA} / \mathrm{m}$, where $B_{\mathrm{r}}$ is residual magnetic flux density and $t$ is thickness of magnetic layer. The hard disk for inductive heads has a $\mathrm{Co}-\mathrm{Ni}-\mathrm{Cr}$ magnetic layer whose $B_{\mathrm{r}} \cdot t$ is $270 \mathrm{G} \cdot \mu \mathrm{m}$ and $H_{\mathrm{c}}$ is $130 \mathrm{kA} / \mathrm{m}$. The hard disk for MR heads has a CoCr-Pt magnetic layer whose $B_{\mathrm{r}} \cdot t$ is $130 \mathrm{G} \cdot \mu \mathrm{m}$ and $H_{\mathrm{c}}$ is $130 \mathrm{kA} / \mathrm{m}$. The measurements of the tape and the disks were performed with the same Metal-InGap (MIG) ring-type head under the condition of contact recording, where gap length was $0.16 \mu \mathrm{m}$ and track width was $6 \mu \mathrm{m}$.

In Fig.5, it is found that the Co-O tape has the highest reproduced voltage and the disk for MR heads has the lowest one. The reproduced voltage at low recording density is almost proportional to $B_{r} \cdot t$. The low reproduced voltage of the disk for MR heads is complemented by using MR heads in hard disk drives. As for the noise, precise estimation has not been performed yet, because of the low head sensitivity. SN ratios are hence not judged from this measurement. It is clear that guide to design magnetic layers for disks is considerably different from that for tapes.

\section{CONCLUSIONS}

The results are as follows.

(1) $H_{c}$ of the films formed directly on the polymer substrate is low at thin thickness region such as 20 $\mathrm{nm}$, having maximum value around thickness of 40 $\mathrm{nm}$, and becomes low over $50 \mathrm{~nm}$.

(2) The $\mathrm{CoO}$ underlayers have the remarkable effect which makes $H_{\mathrm{c}}$ of the Co-O films high in the film thickness region under about several tens $\mathrm{nm}$. This is considered to be owing to the morphology of the $\mathrm{CoO}$ underlayers which consist of isolated grains with diameter of about $10 \mathrm{~nm}$.

(3) The Co-O tapes have much higher reproduced voltage than the disks for MR heads.

\section{REFERENCES}

[1] K. Tohma, R. Sugita, K. Yoshimoto and T. Ishida, J. Magn. Soc. Japan, Vol.21, No.4-2, pp.229-232, 1997.

[2] M. Noda, IEEE Trans. Magn., Vol.27, No.6, pp.4864-4866, 1991.

[3] M. Takahashi, T. Shimatsu, M. Suekane, M. Miyamura, K. Yamaguchi and Y. Yamasaki, IEEE Trans. Magn., Vol.28, No.5, pp.3285-3287, 1992. 